\section{SAT0560 FROM A 2-YEAR MULTICENTRE CLINICAL TRIAL IN KNEE OSTEOARTHRITIS, A METABOLOMIC ANALYSIS REVEALS THAT OVER ACTIVATION OF THE CONVERSION PATHWAY OF PHOSPHATIDYLCHOLINE TO LYSOPHOSPHATIDYLCHOLINE IS ASSOCIATED WITH KNEE CARTILAGE VOLUME LOSS OVER TIME}

G. Zhai ${ }^{1}$, J.-P. Pelletier ${ }^{2}$, M. Liu' ${ }^{1}$, E. Randell ${ }^{3}$, J. Martel-Pelletier ${ }^{2} .{ }^{1}$ Discipline of Genetics, Memorial University of Newfoundland, St. John's, NL; ${ }^{2}$ University of Montreal Hospital Research Centre, Montreal; ${ }^{3}$ Department of Laboratory Medicine, Memorial University of Newfoundland, St. John's, NL, Canada

Background: While progression of osteoarthritis $(\mathrm{OA})$ is variable, no tools yet exist to predict disease course.

Objectives: To identify, using a metabolomic approach, serum marker(s) for predicting knee cartilage volume loss over time measured by magnetic resonance imaging (MRI) in a 24 month Phase III clinical trial in patients with symptomatic knee OA.

Methods: 139 knee OA patients who completed the clinical trial according to protocol were selected from a 24 month DMOAD trial studying the effect of licofelone versus naproxen. MRI was performed at baseline and 24 months. Targeted metabolomic profiling was performed on serum collected at baseline. Metabolite ratios as proxies for enzymatic reaction were calculated and used in the analysis. The levels of 186 metabolites were measured and 152 met the quality control requirements. The metabolite concentrations were standardised using the $Z$ score. 21952 pair wise metabolite ratios were analysed. A metabolome-wide significance level of $a=2.3^{*} 10-{ }^{6}$ was defined after correcting multiple testing with the Bonferroni method. Univariable and multivariable analyses adjusted for age, sex, $\mathrm{BMI}$ and treatment were performed. Gene expression analysis of human OA articular cartilage $(n=32)$ and subchondral bone $(n=39)$ tissues from total joint replacement, and controls (non-OA) from individuals having a fracture $(n=21 ; n=9$, respectively) was done to further explore the potential metabolic pathway(s).

Results: Data revealed that the baseline ratio of the metabolite lysophosphatidylcholine 18:2 (lysoPC 18:2) to phosphatidylcholine 44:3 (PC44:3) was associated with the cartilage volume loss in the lateral compartment (univariable, $b=-0.21$ $\pm 0.04, p=8.53^{*} 10-^{7}$; multivariable, $b=-0.18 \pm 0.04, p=9.5^{*} 10-6$ ). Further experiments demonstrated that the lysoPC $18: 2 / P C 44: 3$ ratio was also significantly $(r=0.31, p=0.0002)$ correlated with an articular degradation marker, COMP. The data of the increased lysoPC 18:2 to PC44:3 ratio involve a conversion pathway of PC to lysoPC which is catalysed by a phospholipase A2 (PLA2), suggesting a higher activity of PLA2. Data demonstrated that in both human cartilage and subchondral bone tissues, a PLA2, PLA2 group 5 (PLA2G5), was markedly overexpressed in OA cartilage and subchondral bone compared to these non-OA tissues $(445 \%$ and $158 \%$ increase, respectively, all $p<0.02)$. Interestingly, in these tissues TNF-a was also upregulated $(p=0.007 ; p=0.06$, respectively), and positively correlated with PLA2G5 $(r=0.71, p=0.02)$.

Conclusions: Our data suggest that the ratio of lysoPC 18:2/PC44:3 is predictive of greater risk of cartilage loss in OA. We speculate that this specific conversion pathway may produce a bioactive molecule like oleoylethanolamide (OEA), which has been demonstrated to bind to a novel cannabinoid receptor, GPR119, thus could be a novel therapeutic target for OA treatment.

Acknowledgements: This work is supported by Canadian Institutes of Health Research. The metabolomic profiling was done at Translational Metabolomics Innovation Centre. The original clinical trial was supported in part by grants from Merckle GmbH (Ulm, Germany) and ArthroLab Inc. (Montreal, Quebec, Canada). Disclosure of Interest: G. Zhai: None declared, J.-P. Pelletier Shareholder of: ArthroLab Inc., M. Liu: None declared, E. Randell: None declared, J. Martel-Pelletier Shareholder of: ArthroLab Inc.

DOI: 10.1136/annrheumdis-2018-eular.5665

\section{SAT0561 MITOCHONDRIAL BACKGROUND INFLUENCES THE JOINT EVOLUTION IN A CONPLASTIC MOUSE MODEL OF AGEING}

I. Rego-Pérez ${ }^{1}$, A.V. Lechuga-Vieco ${ }^{2}$, M. Scotece ${ }^{1}$, P. Filgueira-Fernández ${ }^{1}$, S. Pértega ${ }^{3}$, J.A. Enríquez ${ }^{2}$, F.J. Blanco ${ }^{1}{ }^{1}{ }^{1}$ Servicio de Reumatología, INIBIC HOSPITAL UNIVERSITARIO A CORUÑA, A Coruña; ${ }^{2}$ Grupo de Genética funcional del sistema de fosforilación oxidativa, Centro Nacional de Investigaciones Cardiovasculares (CNIC), Madrid; ${ }^{3}$ Unidad de Epidemiología Clínica y Bioestadística, Inibic - Hospital Universitario A Coruña, A Coruña, Spain

Background: Several studies showed interesting associations between mtDNA haplogorups and different OA-related features, including prevalence, incidence or progression of the disease ${ }^{1-3}$. The use of conplastic animals-individuals with the same nuclear genome but different mtDNA variants-provides an accurate tool to study the influence of the mitochondrial background in the ageing process ${ }^{4}$.

Objectives: To study the influence of mtDNA variation in the degree of joint deterioration of the knees of aged animals using a conplastic mouse model of ageing
Methods: mtDNAs from C57BL/6 and NZB/OlaHsd mice were used. These mtDNAs differ by 12 missense mutations, 4 tRNAs mutations, 8rRNAs mutations and 10 non-coding region mutations. Then, a conplastic mice strain was developed with the C57BL/6 nuclear genome and the NZB/OlaHsd mtDNA (BL/6 ${ }^{\mathrm{NZB}}$ ) to compare with the original $\mathrm{C} 57 \mathrm{BL} / 6$ strain $\left(\mathrm{BL} / 6^{\mathrm{C} 57}\right)$ in animals of 25 and 75 weeks. A total of 38 limbs from 19 mice were processed to perform histologic analyses: 8 $\mathrm{BL} / 6^{\mathrm{NZB}} 25 \mathrm{w}, 10 \mathrm{BL} / 6^{\mathrm{NZB}} 75 \mathrm{w}, 10 \mathrm{BL} / 6^{\mathrm{C} 57} 25 \mathrm{w}$ and $10 \mathrm{BL} / 6^{\mathrm{C} 57} 75 \mathrm{w}$.

Results: Mankin score data showed significantly increased values in all knees from both strains at $75 w$ compared with $25 w(p<0,001)$, confirming the ageing of the joint. When $75 \mathrm{w}$ mice were selected (table 1 ), the BL/6 ${ }^{\mathrm{C} 57}$ strain showed a significantly increased score in whole joint $(p=0,038)$, femoral condyles $(p=0,021)$ and medial femoral condyle $(p=0,015)$ than $B / 6^{\mathrm{NZB}}$ strain. Safranin-O/Fast-green ration value at $75 \mathrm{w}$ was higher in the medial compartment of $\mathrm{BL} / 6^{\mathrm{NZB}}$ compared with $\mathrm{BL} / 6^{\mathrm{C} 57}$ (both tibial plateau and femoral condyle); however, only the differences detected in the medial compartment of the tibial plateau reached the statistical significance $(p<0,001)$, whilst the differences detected in the femoral condyle borderline the statistical significance $(p=0,091)$.

The width of the epiphyseal plate was analysed in both tibia and femur bones. The results showed significantly decreased values in $\mathrm{BL} / 6^{\mathrm{C} 57}$ at $75 \mathrm{w}$ compared with the same strain at $25 w$ in tibial plateau $(p<0,001)$ and femoral condyle $(p=0,049)$; however, these differences were not observed in animals belonging to BL/6 ${ }^{\mathrm{NZB}}$ strain. In addition, the $\mathrm{BL} / 6^{\mathrm{C} 57} 75 \mathrm{w}$ strain also showed significantly lower values in tibial plateau than $\mathrm{BL} / 6^{\mathrm{NZB}}$ strain at the same age $(p=0,032)$

Abstract SAT0561 - Table 1. Mankin score grading of cartilage destruction in conplastic mice $\mathrm{BL} / 6^{\mathrm{C} 57}$ and $\mathrm{BL} / 6^{\mathrm{NZB}}$ at $75 \mathrm{~W}$

\begin{tabular}{lccccccccc}
\hline & LTP & LFC & MTP & MFC & TP & FC & $\begin{array}{c}\text { Med } \\
\text { comp }\end{array}$ & $\begin{array}{c}\text { Lat } \\
\text { comp }\end{array}$ & $\begin{array}{c}\text { Whole } \\
\text { joint }\end{array}$ \\
\hline BL/ & 5,80 & 4,40 & 4,67 & 6,00 & 10,44 & 10,37 & 10,14 & 10,20 & 19,71 \\
$\mathbf{6}_{\text {C57 }}$ & $\pm 1,81$ & $\pm 1,07$ & $\pm 2,06$ & $\pm 1,07$ & $\pm 3,43$ & $\pm 1,85$ & $\pm 3,02$ & $\pm 2,39$ & $\pm 4,57$ \\
BL/ & 5,00 & 4,38 & 4,40 & 4,44 & 9,40 & 8,71 & 8,44 & 9,13 & 17,43 \\
$\mathbf{6}^{\text {NZB }}$ & $\pm 2,11$ & $\pm 0,92$ & $\pm 2,12$ & $\pm 1,24^{*}$ & $\pm 1,78$ & $\pm 1,70^{*}$ & $\pm 2,60$ & $\pm 1,55$ & $\pm 1,72^{*}$ \\
\hline
\end{tabular}

LTP: lateral tibial plateau; LFC: lateral femoral condyle; MTP: medial tibial plateau; MFC: medial femoral condyle; TP: tibial plateau; FC: femoral condyle; Med comp: medial compartment; Lat comp: lateral compartment; ${ }^{*} \mathrm{p}<0,05$ with respect to $\mathrm{BL} / 6^{\mathrm{C} 57}$

Conclusions: This study demonstrates the functional impact of mtDNA variation in the process of joint deterioration associated to ageing, leading to consider the mtDNA as a potential therapeutic target in osteoarthritis associated to ageing

\section{REFERENCES:}

[1] Shen, et al. PLoS One 2014;9(10):e108896.

[2] Fernández-Moreno, et al. Ann Rheum Dis 2017;76(6):1114-1122.

[3] Fernández-Moreno, et al. Rheumatology 2017;56(2):263-270.

[4] Latorre-Pellicer, et al. Nature2016;535(7613):561-5.

Disclosure of Interest: None declared

DOI: 10.1136/annrheumdis-2018-eular.4544

\section{SAT0562 HIP SHAPE PREDICTS KNEE OSTEOARTHRITIS OUTCOMES OVER A DECADE IN OLDER-ADULTS}

I.P. Munugoda ${ }^{1}$, H.G. Ahedi ${ }^{1}$, R.M. Aspden ${ }^{2}$, K. Wills ${ }^{1}$, S.E. Graves ${ }^{3}$, M. Lorimer ${ }^{4}$, F. Cicuttini ${ }^{5}$, J.S. Gregory ${ }^{2}$, G. Jones ${ }^{1}$, M.L. Callisaya ${ }^{1}$, D. Aitken ${ }^{1} .{ }^{1}$ Menzies Institute for Medical Research, University of Tasmania, Hobart, Tasmania, Australia; ${ }^{2}$ Aberdeen Centre for Arthritis and Musculoskeletal Health, Institute of Medical Sciences, University of Aberdeen, Aberdeen, UK; ${ }^{3}$ Australian Orthopaedic Association National Joint Replacement Registry (AOANJRR); ${ }^{4}$ South Australian Health and Medical Research Institute (SAHMRI), Adelaide, South Australia; ${ }^{5}$ Department of Epidemiology and Preventive Medicine, Monash University Medical School, Melbourne, Victoria, Australia

Background: Various hip shapes may be important as a risk factor for development and progression of knee osteoarthritis, due to the biomechanical link between the two joints.

Objectives: This study aims to identify the relationship between hip morphology and structural and clinical osteoarthritis outcomes in the knee over 10.7 years, in older-adults.

Methods: 377 community-dwelling older-adults aged 50-80 years were studied. At baseline, dual-energy $\mathrm{X}$-ray absorptiometry images of the left hip were obtained and hip shapes were described using mode scores from an 85-point statistical shape model. MRI scans were conducted at baseline and a mean follow-up of 10.7(SD:0.67) years later, to assess right knee tibial cartilage volume and bonemarrow lesions(BMLs). Knee pain was assessed using Western Ontario and McMaster Universities Osteoarthritis Index(WOMAC). Knee replacement(KR) data were obtained by data linkage to the Australian Orthopaedic Association National Joint Replacement Registry. Linear mixed-effects, log-binomial models 